\title{
Análise de uma experiência de letramento na perspectiva da educação em direitos humanos
}

Analisys of a literacy experiment under the perspective of human rights education

\author{
Cristiane Fontes Oliveira* \\ EMEIF do Campo Eugênio Trovatti \\ Emília Freitas de Lima** \\ Universidade Federal de São Carlos
}

Resumo $\mathrm{O}$ artigo pretende promover uma reflexão sobre a necessidade de implementação prática, no quotidiano escolar, da Educação Intercultural e em Direitos Humanos, com foco na temática de gênero. Nesse sentido, apresentamos um conjunto de procedimentos didático-pedagógicos, realizados no contexto de aulas da disciplina de Língua Portuguesa, que tiveram como objetivo problematizar com estudantes, por meio de práticas de letramento, a situação da mulher na contemporaneidade. Nesse contexto, a metodologia proposta por Paulo Freire foi apresentada como ferramenta privilegiada para transpor da teoria à prática tal Educação. Assim, mediante a análise da vivência de estudantes (sujeitos da pesquisa) em Círculos de Cultura, tendo como tema gerador o sexismo, constatamos que a educação escolar pode conduzir o(a) aluno(a) de uma consciência alienada para uma consciência crítica.

PALAVRAS-CHAVE: Educação em direitos humanos; Letramento; Educação intercultural.

\begin{abstract}
This article intends to promote a reflection about the necessity of a practical implementation of the Intercultural Education and Human Rights in school environment with focus on the genre thematic. In this way, we present a set of pedagogical teaching procedures, applied in the context of Portuguese language classes, which had as a goal to problematize with the students, through literacy practices, by the women situation in the modern days. In this context, the methodology proposed by Paulo Freire was presented as a special tool to bridge from the theory to the practice in this referred Education. Therefore, by the analysis of students life experiences (subjects of this research) in the Culture Circles, and having sexism as a generating theme, we found that school education may lead the student from an alienated conscience to a critical conscience.
\end{abstract}

KEYWORDS: Education in human rights; Literacy; Intercultural education. 


\section{Introdução}

Este artigo foi elaborado a partir de um projeto pedagógico denominado "Mulheres e Homens pela Igualdade entre os Sexos", desenvolvido nas aulas de Língua Portuguesa de uma turma de $6^{\circ}$ ano de uma escola pública de Limeira, interior paulista, em 2009. Este projeto pedagógico foi concebido a partir da defesa da necessidade de implementação, no contexto escolar, da Educação Intercultural e em Direitos $\mathrm{Hu}$ manos. Teve como orientação a perspectiva de que a educação escolar pode contribuir para formar estudantes não somente dotados de conhecimentos científicos, mas que também sejam cidadãs e cidadãos aptos ao exercício constante do respeito, da ética, da justiça, da igualdade em todos os âmbitos da vida social, ou seja, orientou-se por princípios advindos das teorias acerca da Educação Intercultural e em Direitos Humanos.

A Educação Intercultural, que tem como base teórico-conceitual os estudos sobre multiculturalismo - ou interculturalismo, como prefere denominar Candau (2005, p. 28-35), referindo-se às discussões sobre o contato entre diferentes culturas, tem como objetivo fundamental promover uma educação que respeite e valorize as diversas culturas em seus diversos contextos de existência. Tais estudos nascem a partir das lutas sociais pela valorização de determinadas identidades marginalizadas por culturas dominantes como as lutas dos negros, indígenas, homossexuais, mulheres, enfim, de todos(as) aqueles(as) subjugados historicamente pelo dominante padrão branco, masculino, eurocêntrico e heterossexual. Nesse sentido, Candau (2008) começa a aproximar o conceito de Educação Intercultural ao de Educação em Direitos Humanos, que da mesma maneira, nasce a partir das reivindicações de frações de classes sociais oprimidas historicamente em relação às suas condições de direitos. Portanto, compreende-se que uma educação que possibilite um contato respeitoso e harmonioso entre diferentes culturas também é uma educação que promove e ensina Direitos Humanos, ou seja, uma está implicada na outra. Assim, pode-se entender que se trata de um mesmo tipo de educação, por promover a humanização.

Pensada dessa forma, a direção do ato educativo na prática da Educação Intercultural e em Direitos Humanos pauta-se por uma concepção de educação voltada para o aprimoramento dos seres humanos e das culturas. Nesse sentido, tal concepção, neste trabalho, foi considerada em relação ao combate ao sexismo e, para tal, o foco foi o da Educação Intercultural e em Direitos Humanos.

Embora a temática da relação entre os sexos tenha delimitado o projeto de intervenção analisado neste artigo, acreditamos que os procedimentos descritos possam ser aplicados em diferentes contextos, com outras temáticas relacionadas ao contato entre diferentes culturas, ou mesmo aos diversos eixos que possuem os Direitos Humanos, tais como os direitos das crianças e adolescentes, os direitos dos povos negros e indígenas, dos idosos, das pessoas com necessidades especiais, entre outros.

O projeto nasceu da indagação: como colocar em prática, no contexto escolar, a Educação Intercultural e em Direitos Humanos? Foi inspirado nas experiências de Candau et al. (1995) com as chamadas oficinas em direitos humanos, aplicadas, em grande parte, na ONG Nova América, as quais têm como intuito a formação de educa- 
dores(as) no tema dos Direitos Humanos, e também em um artigo intitulado Direitos Humanos, educação e interculturalidade: as tensões entre igualdade e diferença ${ }^{1}$ (CANDAU, 2008). Neste artigo a autora revela que os principais desafios da Educação Intercultural e em Direitos Humanos estão relacionados à desconstrução de paradigmas que parecem naturais, mas que são articulados em prol de determinados grupos, com a finalidade de subjugar outros; à articulação com o intuito de garantir que a igualdade se explicite nas diferenças, objetivando romper com o caráter monocultural da cultura escolar; ao resgate dos processos de construção das identidades culturais, no âmbito pessoal e coletivo, para evidenciar que as culturas estão em contínuo movimento e em diálogo com outras; e à promoção da interação com os "outros/as", para que as pessoas possam ser capazes de relativizar suas próprias maneiras de se situarem diante do mundo e atribuir-lhe sentido. O objetivo fundamental para Candau (2008) é promover o "empoderamento" de grupos historicamente marginalizados.

Com base nessas categorias referidas por Candau (2008) - Educação Intercultural e Educação em Direitos Humanos -, o projeto pedagógico de intervenção, aqui analisado, pautou-se nas ideias de desconstrução de uma ideologia machista; de articulação para a busca de uma nova configuração de práticas de letramento; de resgate de uma identidade feminina consciente das relações sociais de dominação existente entre os sexos e de uma educação consciente de sua direção política e, portanto, dotada de posicionamento crítico; e de interação, no sentido de que os(as) estudantes puderam juntos(as) elaborar novas posturas de valores sobre a situação da mulher na atualidade e sua condição de direitos.

O projeto foi denominado de "projeto pedagógico de intervenção", por ter como objetivo intervir em uma situação, alterando-a no sentido de desconstruir posturas machistas manifestadas pelos(as) estudantes e, para alcançar tal objetivo, o contexto foi o da educação escolar. Coerentemente com este objetivo, e entendendo que a obra de Paulo Freire proporcionaria o referencial mais adequado à abordagem pedagógica da temática em tela, optamos pela utilização da metodologia de ensino inspirada nos Círculos de Cultura ${ }^{2}$.

\section{Paulo Freire e a pedagogia da interculturalidade e dos di- reitos humanos}

De acordo com Padilha (2005, p. 167), foi pensando nos oprimidos, nos(as) historicamente marginalizados(as), que Freire criou sua obra, na qual apresenta a educação como uma prática que pode auxiliar homens e mulheres na "libertação das injustiças históricas, econômicas, políticas e sociais, cuja superação passaria necessariamente pela educação como 'prática da liberdade' e considerada em sua radicalidade criadora".

Freire fundamenta o processo de alfabetização em alguns procedimentos que, em síntese, correspondem a um levantamento do universo vocabular, ou seja, das palavras que estão mais presentes no quotidiano dos alunos e alunas e, em seguida, realiza a escolha das palavras geradoras, isto é, as que centralmente representam o campo lexical do(a) aluno(a). Tais palavras devem ser escolhidas de acordo com a rele- 
vância fonêmica e com seu engajamento na realidade social, cultural e política dos(as) alunos(as). Posteriormente, constituem-se os Círculos de Cultura, ou seja, grupos formados por alguns(mas) alunos(as), com a coordenação de uma pessoa; em seguida apresenta-se a representação gráfica das palavras, e estas devem pertencer ao universo vocabular dos educandos(as), ou seja, às suas experiências de vida. Por meio de tais procedimentos, pretende-se gerar temas correlatos que devem suscitar reflexões sobre o contexto de existência dos(as) educandos(as), dando origem aos "Temas Geradores", que são os assuntos que devem partir da realidade social e cultural na qual os(as) educandos(as) estão inseridos(as), tendo a potencialidade de gerar debates e reflexões sobre determinados contextos.

Freire também idealiza um processo semelhante para o período de pós-alfabetização, que deve estar relacionado ao texto e não mais à palavra, e é nesta etapa, ou seja, a da pós-alfabetização, que se centrou o projeto pedagógico de intervenção que descreveremos nesta exposição.

As atividades de alfabetização e de pós-alfabetização devem partir da consciência da realidade do(a) educando(a), mesmo que esta seja uma consciência deturpada, permeada de ideologias que apresentam a "sombra do opressor" no oprimido, para, posteriormente, irem ao encontro de outras consciências sobre a realidade social, ou seja, de consciências verdadeiras, reais, sobre o processo de opressão vivenciado pelos(as) oprimidos(as).

A partir das obras de Kato (1986), Kleiman (1995), Soares (1998) e outras autoras e autores que discorrem sobre alfabetização, pesquisadores do tema e professores alfabetizadores passam a entender que é necessário algo mais para o(a) educando(a) atingir o estágio pleno da alfabetização, ou seja, não basta apenas que a pessoa saiba escrever e ler a palavra, é necessário saber interpretá-la dentro do contexto em que é utilizada e, na atualidade, tal estágio denomina-se "letrado(a)", isto é, aquele(a) que consegue usar com proficiência a linguagem de acordo com as diversas necessidades comunicativas, de maneira que interprete as situações sociais e as traduza por meio da linguagem oral ou escrita.

Para Freire, esse "algo mais" é a criticidade, a capacidade de interpretar o mundo. Ambos os conceitos, portanto, admitem que não basta para o(a) educando(a) saber decodificar e reconstituir símbolos gráficos, pois para as duas concepções a interpretação e recriação crítica e contextualizada da linguagem constituem a nota fundamental do processo de aquisição da competência leitora e escritora. Freire (1992) nos apresenta o conceito de "palavra mundo", isto é, para ele a palavra é acima de tudo significado, e não meramente grafia e pronúncia.

Portanto, entende-se o conceito de letramento, no projeto pedagógico realizado e no contexto desta exposição, como prática sociocultural, pois, de acordo com Soares (2004, p. 90), a pessoa deve ser ensinada a ler e escrever para uso em situações da vida social, tendo domínio de conhecimentos, habilidades e atitudes linguísticas. Ou seja, partilha-se da concepção, como Justo e Rubio (2013, p. 05) apresentaram, a partir da análise dos principais referenciais do conceito de letramento, de que letrar, na 
abordagem sociocultural, é formar para a cidadania, na medida em que pode ampliar ao sujeito o domínio da informação de maneira que não ocorra a simples assimilação dos saberes, mas a assimilação consciente e, no dizer de Freire (1992), a assimilação crítica.

\section{O percurso do projeto pedagógico de intervenção "mulhe- res e homens pela igualdade entre os sexos"}

O projeto pedagógico de intervenção "Mulheres e Homens pela Igualdade entre os Sexos" objetivou promover nos(as) estudantes reflexões acerca das relações entre os sexos em nossa sociedade, especificamente sobre a situação da mulher na atualidade e sua condição de direitos, a fim de que os(as) estudantes pudessem construir ideias/pensamentos que fossem ao encontro das concepções feministas.

À época de implantação do projeto, a primeira autora deste artigo atuava como professora de Língua Portuguesa dos(as) estudantes participantes da pesquisa. Assim, inicialmente, por meio de uma sondagem realizada nas entrevistas, delimitouse o campo temático de atuação, dentro da perspectiva ampla na qual se delineiam as discussões feministas. Em seguida, a partir das impressões tidas com as leituras das respostas das entrevistas, delimitaram-se os textos que seriam trabalhados nos Círculos de Cultura, com o objetivo de "desconstruir" estereótipos sobre homens e mulheres manifestados pelos(as) estudantes/sujeitos da pesquisa.

Os(as) estudantes da turma de $6^{\mathrm{a}}$ série selecionada ${ }^{3}$ vivenciaram, durante o período de três meses, momentos de leitura, análise e interpretação de contos da escritora Marina Colasanti, que abordavam a temática das relações entre mulheres e homens, assim como de textos informativos que tratavam da situação e dos direitos das mulheres; prática que compôs uma atividade de desenvolvimento da competência leitora, interpretativa e argumentativa na disciplina de Língua Portuguesa. Depois, foi solicitado aos(às) estudantes que elaborassem artigos de opinião sobre a necessidade da luta das mulheres na atualidade, prática que se configurou como uma atividade de desenvolvimento da competência escritora. Nos artigos, os(as) estudantes foram instados a responder a seguinte indagação: "Ainda é preciso que as mulheres lutem para terem uma condição de vida mais justa em relação à dos homens?”.

As atividades do projeto possibilitaram, portanto, que os(as) estudantes praticassem a leitura e escrita de textos, lembrando que os textos criados pelos(as) alunos(as) eram submetidos aos procedimentos típicos das práticas de ensino de produção textual, como revisão gramatical e reflexão sobre o gênero textual estudado.Os procedimentos descritos anteriormente ocuparam o período de um trimestre, fazendo-se uso de três a quatro horas-aula semanais - destacamos que a disciplina de Língua Portuguesa possui carga horária de cinco horas-aula semanais na instituição onde os dados foram coletados - e, nas aulas restantes, foram trabalhados os demais conteúdos relacionados à disciplina. 


\section{O percurso da pesquisa}

O objetivo foi o de analisar a contribuição dos Círculos de Cultura, tendo como Tema Gerador a situação da mulher na atualidade e sua condição de direitos, para o desenvolvimento das ideias/pensamentos dos(as) estudantes sobre o tema, na perspectiva das relações sociais entre homens e mulheres.

Para a consecução de tal objetivo, inicialmente foi realizada uma entrevista em grupo com os(as) estudantes selecionados(as), no sentido de se tentar compreender quais seriam as percepções deles(as) em referência às relações e identidades de gênero de homens e mulheres e quais os juízos de valor que traziam consigo, isto é, qual a concepção que manifestavam sobre as relações sociais entre os sexos, antes do início dos primeiros procedimentos do projeto "Mulheres e Homens pela Igualdade entre os Sexos".

A entrevista, além de servir como base para a seleção dos textos debatidos nos Círculos de Cultura, também foi utilizada para a seleção dos participantes da pesquisa, pois a intenção foi a de analisar os dados referentes aos(às) estudantes que manifestaram ideias/pensamentos sexistas. Foram escolhidos oito estudantes da turma já explicitada no item anterior, sendo quatro meninos e quatro meninas, que manifestavam concepções machistas, detectadas a partir da entrevista inicial. Optou-se por um grupo pequeno de participantes, levando-se em consideração a quantidade de material de análise que a pesquisa geraria.

O estudo foi apresentado para quatro alunos e quatro alunas e para seus respectivos responsáveis, sendo convidados(as) a participarem de maneira voluntária da pesquisa, assinando, inclusive, termos de consentimento de participação. Não foi mencionado a eles o fato de apresentarem uma postura sexista frente às relações sociais entre os sexos, para que tais estudantes agissem com naturalidade. Do contrário, poderiam procurar elaborar opiniões não sexistas durante o estudo para atender aos anseios da pesquisa, isto é, escrevessem o que, de acordo com suas concepções, a pesquisadora esperava que fosse escrito.

Assim, o intuito era o de poder, a partir de tal entrevista, acompanhar possíveis mudanças de posturas em relação a valores sobre homens e mulheres durante a vivência dos procedimentos metodológicos. $\mathrm{E}$, por fim, os sujeitos elaboraram artigos de opinião, a partir de suas experiências nos Círculos de Cultura, nos quais puderam revelar as suas concepções sobre a condição da mulher.

Durante a vivência dos(as) alunos(as) nos Círculos de Cultura, a pesquisadora realizou anotações em um diário de campo sobre observações acerca das experiências relacionadas aos procedimentos metodológicos vivenciados e das reações dos oito sujeitos da pesquisa a eles. A interpretação dos dados das entrevistas, das redações (artigos de opinião) e do diário de campo deu-se a partir de técnicas relacionadas à Análise de Conteúdo e foi fundamentada nos estudos de Paulo Freire, na perspectiva da Educação Intercultural e em Direitos Humanos, no que se refere ao combate do sexismo. O estudo teve como foco a visão dos educandos(as) sobre a situação e condição de direitos das mulheres na atualidade. 
Em síntese, avaliou-se a potencialidade do projeto de intervenção por meio da análise das entrevistas, dos textos produzidos pelos alunos e alunas a partir de suas experiências nos Círculos de Cultura (do gênero textual artigo de opinião) e do diário de campo que a pesquisadora elaborou. Este diário continha relatos de acontecimentos do ambiente de estudo, os quais contribuíram para a análise dos dados, pois possibilitaram a contextualização do leitor da pesquisa sobre o quotidiano da coleta de dados. Assim, além dos textos elaborados pelos(as) alunos(as), também se configurou como material de análise o conjunto de informações contidas no diário de campo.

\section{Toda palavra, sim, é uma semente4: os resultados da pes- quisa}

Foram delimitadas, para a análise dos dados, algumas unidades de registro que foram categorizadas em função dos temas e subtemas mais frequentes que surgiram a partir da análise preliminar das entrevistas iniciais. Assim, tais unidades foram definidas a posteriori e se relacionam, segundo Freire (1992), a "sombra do opressor", ou seja, a ideologia machista presente em homens e mulheres. As categorias referidas foram formuladas, principalmente, a partir de um documento internacional fundamental da luta feminista: a Carta Mundial das Mulheres à Humanidade (2008)5.

A partir da análise das reivindicações históricas dos movimentos sociais de mulheres - que expressam os desafios da luta feminista contemporânea, desafios estes já destacados por Saffioti (1987) e Whitaker (1997), que na década de 1980 denunciavam a repressão vivenciada pelas mulheres desde a primeira infância, é que formulamos as categorias de análise dos dados coletados, tendo como base, também, conforme anteriormente citado, os temas e subtemas mais frequentes nas entrevistas. Portanto, a seguir são apresentados os conteúdos semânticos que se configuram em três eixos de análise das entrevistas:

\section{Representação dos homens e mulheres no exercício dos trabalhos e brincadeiras}

Os(as) estudantes manifestavam o pensamento de que as mulheres devem exercer atividades relacionadas ao cuidado com o lar e com os(as) filhos(as), isto é, as atividades femininas devem ser executadas, em sua grande maioria, dentro de casa; e os homens devem exercer atividades que garantam o custeio financeiro da família, ou seja, suas atividades devem ser, na maioria dos casos, exteriores ao ambiente doméstico. No mesmo aspecto, representavam os homens como sujeitos aptos a desenvolverem atividades que exijam maior força física, enquanto o trabalho feminino é tido como mais fácil e que exige menos esforço físico. No universo infantil das brincadeiras, as meninas devem promover, segundo as concepções manifestadas, brincadeiras que se associem simbolicamente com a casa e com a família, tal como brincar de casinha; já os meninos devem promover brincadeiras que se associem às atividades esportivas ou a aparatos tecnológicos, como brincar de futebol ou carrinho, respectivamente. 


\section{Representação comportamental da identidade masculina e feminina}

Nesta categoria se inserem as representações relacionadas ao cuidado com o corpo feminino, no sentido de apresentar a mulher como um sujeito que deve estar mais preocupado com a aparência estética que o homem, e deve seguir determinados rituais de embelezamento, a fim de corresponder, isto é, agradar, aos anseios masculinos. Neste tópico também se inserem as argumentações que vão ao encontro de expressar pensamentos que idealizam as mulheres como objetos a serem olhados e tutelados pelos homens, caracterizando-as como seres fracos (sensíveis), que devem estar sob o cuidado constante da virilidade masculina. Assim, tal perspectiva desconsidera a força e a autonomia feminina. Insere-se, ainda, o pensamento de que é função dos homens o custeio financeiro da casa (este item também se vincula à categoria anterior), desconsiderando a inserção das mulheres no mundo do trabalho, vinculando-a como dependente, isto é, subjugada ao trabalho remunerado masculino.

\section{Pensamentos sobre a luta feminista na contemporaneidade}

$\mathrm{Na}$ opinião dos(as) estudantes, as mulheres já possuem igualdade de direitos em relação à vida dos homens, e vivemos em uma sociedade com total equidade no âmbito das relações entre os sexos. Esses(as) estudantes até podem conceber que décadas atrás as mulheres eram vítimas de violência, discriminação, mas acreditam que na atualidade, sobretudo por supostamente terem acesso à profissionalização e emprego, elas têm igualdade de oportunidades e possuem condições de vida igual à dos homens.

Quando os educandos e educandas manifestam alguns dos pensamentos e valores descritos que se relacionam a uma das categorias formuladas, eles poderiam revelar uma visão feminista das relações entre os sexos, ou seja, imaginar que homens e mulheres devem partilhar as atividades domésticas, que as mulheres são tão fortes e capazes como os homens para desenvolver qualquer tipo de atividade profissional e que as mulheres ainda têm muitas reivindicações, haja vista a realidade ainda chocante de inúmeros casos de violência, das mais diversas maneiras, e preconceitos contras elas. Contudo, os(as) estudantes revelaram, na maior parte das ocorrências, pensamentos e valores que manifestam a presença da ideologia machista em seus discursos.

Após a vivência no projeto escolar "Mulheres e Homens pela Igualdade entre os Sexos", verificou-se que (em síntese) em relação à alteração de uma postura machista para uma feminista, um sujeito apresentou alteração significativa na categoria 1, não houve alteração na categoria 2 e todos, ou seja, oito, apresentaram alteração na categoria 3. Embora não tenha ocorrido alteração significativa nas categorias 1 e 2, a categoria 3 apresentou alteração em todos os alunos.

Esse diagnóstico foi obtido por meio do confrontamento dos dados da entrevista inicial (que foi utilizada justamente para verificar as ideias prévias dos sujeitos da pesquisa sobre a condição da mulher na contemporaneidade) frente aos dados coletados nos artigos de opinião produzidos pelos alunos e alunas. Portanto, por meio desses dois instrumentos de coleta de dados aliados ao diário de campo, no qual se relatou todo o percurso da vivência dos(as) alunos(as) nos Círculos de Cultura, chegamos a 
esses dados. Assim, revelou-se que os procedimentos didático-metodológicos dos Círculos de Cultura, em uma situação de letramento, podem contribuir para um despertar de consciências feministas sobre as identidades e relações entre mulheres e homens.

As pesquisadoras não ousaram acreditar que o projeto, em suas limitações, alteraria totalmente, em um curto período de tempo, as consciências dos alunos e alunas sobre as relações sociais entre homens e mulheres. Buscou-se, sim, realizar um primeiro passo, podendo, felizmente, revelar que a educação escolar pode desenvolver o papel de conscientizar os(as) educandos(as) sobre as ideologias que permeiam as culturas e agir em prol do aprimoramento delas.

Acredita-se que o projeto de intervenção descrito pôde contribuir para a desnaturalização de processos ideológicos disseminados socialmente, que visam à repressão das mulheres, na contramão da naturalização de tais processos que, segundo Saffioti (1987, p. 11), constituem "o caminho mais fácil e curto para legitimar a 'superioridade' dos homens, assim como a dos brancos, a dos heterossexuais, a dos ricos". Trata-se, pois, de uma consciência deturpada de que as relações sociais são como são em razão de fatores naturais da vida social (biológicos ou alheios à interferência humana) e são, portanto, imutáveis, o que não é verdade, pois estas relações são construídas historicamente pela ação humana e podem ser alteradas.

Para essa apresentação, selecionamos alguns trechos dos artigos de opinião elaborados pelos alunos que participaram como sujeitos da pesquisa (denominados na pesquisa como "Aluno E", "Aluno F", "Aluno G" "Aluno H"), pois foram os que mais demonstraram em seus argumentos, na ocasião da entrevista inicial, ideias machistas. Esses textos exemplificam a conquista de uma consciência feminista sobre a mulher na contemporaneidade, a partir do próprio contexto em que vivem, e também promovem os alunos à condição de sujeitos letrados:

Aluno E:

As mulheres não conquistaram tudo

As mulheres não conquistaram tudo o que era para conquistar, mas há pessoas que falam que elas já conquistaram.

Tem mulheres que tentam conquistar mais, mas não conseguem porque não têm estudo. Há muitas mulheres que não têm uma condição de vida boa, porque são negras, geralmente sofrem mais preconceito, além de serem negras e pobres, elas também são as mais afetadas na hora de arrumar emprego com carteira assinada, têm salário baixo, etc.

[...]

Há países que as mulheres não podem mostrar seu rosto, não podem votar, e nem ir a determinados lugares, e isso vai acabar um dia porque as mulheres vão conquistar isso e muito mais nessa parte.

$[\cdots]$

É por tudo que disse é que acredito que as mulheres não conquistaram tudo e, por isso, têm que continuar lutando. 
Aluno F:

\section{As mulheres têm de ter o direito}

Muitas pessoas acham que as mulheres já conquistaram tudo e eu acho que isto não está certo.

$[\cdots]$

Aqui em Limeira também tem uma coisa que as mulheres não podem fazer: na Maçonaria as mulheres não podem entrar, porque segundo dizem as mulheres não sabem guardar segredo.

Se tudo mudasse, nós teríamos as cidades, as igrejas e um mundo muito feliz com a mudança, e ai que nós vamos viver em um mundo mais justo.

[...]

Aluno G:

\section{A violência contra a mulher}

Eu acho que as mulheres precisam lutar para conquistar algo a mais nas suas vidas, porque os homens acham que são melhores que as mulheres, mas muitas mulheres são mais trabalhadoras e batalhadoras do que os homens, e também podem viver sem eles.

Muitos casos são quando os homens se drogam e bebem demais e acabam batendo em suas mulheres.

$[.$.

Por isso acredito que as mulheres sofrem preconceito e violência e devem lutar para ter uma condição de vida igual à dos homens.

Aluno H:

\section{De onde vem a violência?}

Ela acontece porque em nossa sociedade muita gente pensa que batendo em sua mulher resolve alguma coisa. Mas não, acaba piorando mais ainda e ela vai se tornando uma pessoa agressiva e violenta.

$[\ldots]$

Muitas pessoas adotaram a Lei Maria da Penha. E eu acho sim que deve existir a Lei Maria da Penha para diminuir os atendimentos nos hospitais de mulheres agredidas pelos homens.

$[\cdots]$

E eu também acho que as mulheres têm que lutar para conquistar o que têm que conquistar.

Pode-se notar que os alunos usam informações que aprenderam nos Círculos de Cultura para dissertar sobre o tema e apresentam uma opinião diferente daquela que demonstraram na entrevista inicial, ou seja, se no início do projeto acreditavam que a mulher já havia conquistado todo o necessário e que, portanto, a luta feminista não se justificaria, ao final do projeto entenderam que a condição de vida da mulher 
no Brasil e no mundo ainda é precária e que ainda há muito pelo o que lutar, no que se refere à conquista de direitos pela população feminina.

\section{Considerações finais}

Acreditamos que trabalhar, no contexto escolar, valores e direitos socialmente construídos pode ser uma atividade permanente, não tida unicamente como projeto extracurricular ou tema transversal, realizada esporadicamente a partir da ação de uma determinada escola ou de um educador ou educadora. A atual legislação educacional $^{6}$ legitima a necessidade de que o aluno ou aluna tenha acesso, no contexto escolar, a conhecimentos relativos à construção histórica, cultural e ideológica na qual se constituem práticas e valores sociais. Nesse sentido, cabe à educação escolar ensinar práticas e valores voltados à disseminação de atitudes não sexistas, não racistas, não homofóbicas, não xenofóbicas, ou seja, voltadas ao respeito, à tolerância e à paz entre homens e mulheres.

Freire (1983) mostra-nos um possível caminho para a criação de outro modelo de sociedade, na qual possamos vivenciar a justiça social e a igualdade de deveres e oportunidades para todos e todas, ou seja, a maneira mais plena da concretização dos Direitos Humanos: a conscientização da população, que, segundo o autor, pode dar-se por meio de uma prática educativa que forme não somente pessoas para atuarem no mercado de trabalho, mas que sejam habilitadas para viver socialmente de maneira crítica e consciente de que "o amanhã não é algo pré-dado, mas um desafio, um problema” (FREIRE, 1996, p. 75), interrogando os fatos, investigando e transformando a sua própria realidade. Freire (1983) não indica a educação como a grande salvadora de homens e mulheres dos problemas sociais vivenciados diariamente, mas coloca-a como detentora de um importante papel para a construção de uma sociedade que realmente coloque em prática os Direitos Humanos.

Entendemos que a educação escolar, em sua proposta curricular, precisa contemplar a Educação Intercultural e em Direitos Humanos, pois, o despertar da criticidade, da politização, do respeito e ética devem ser saberes disseminados por todas as disciplinas, afinal, como nos ensinou Nelson Mandela (2014): "Ninguém nasce odiando outra pessoa pela cor de sua pele, por sua origem ou ainda por sua religião. Para odiar, as pessoas precisam aprender, e se podem aprender a odiar, podem ser ensinadas a amar". Freire (1983) acreditava que é um compromisso ético do professor problematizar questões sociais, auxiliando os alunos a conceberem homens e mulheres como os grandes responsáveis pelos modos de vida, ou seja, pela condição de vida humana, capazes de mudar a realidade em que vivem, e desse compromisso ético (e também pedagógico) a educação escolar não deve se abster.

\section{Referências}

BRASIL. Resolução n. 1, de 30 de Maio de 2012. Estabelece diretrizes nacionais para a educação em direitos humanos. Disponível em: <http://portal.mec.gov.br/index.php?option=com_ content\&view=article\&id=17810\&Itemid=866>. Acesso em: 13 fev. 2014. 
CANDAU, V. M. Direitos humanos, educação e interculturalidade: as tensões entre igualdade e diferença. Revista Brasileira de Educação, Rio de Janeiro,v. 13, n. 37, jan./abr. 2008, p. 45-56. 2005, 168 p.

(Org.). Cultura(s) e educação: entre o crítico e o pós-crítico. Rio de Janeiro: DP\&A,

CANDAU, V. M. et al. Oficinas pedagógicas de direitos humanos. 4. ed. Petrópolis: Vozes, 1995, 125p.

CARTA mundial das mulheres à humanidade. Disponível em: <http://www.umarfeminismos. org/images/stories/pdf/cartamundialdasmulheresparaahumanidade.pdf>. Acesso em: 22 fev. 2014.

FREIRE, P. Educação como prática da liberdade. 16. ed. Rio de Janeiro: Paz e Terra, 1983, $150 \mathrm{p}$.

Pedagogia da autonomia: saberes necessários à prática pedagógica. 33. ed. São Paulo: Paz e Terra, 1996, 148p.

Pedagogia da esperança: um encontro com a pedagogia do oprimido. Rio de Janeiro: Paz e Terra, 1992, $245 \mathrm{p}$.

JUSTO, M. A. P. S.; RUBIO, J. A. S. Letramento: O uso da leitura e da escrita como prática social. Revista Eletrônica Saberes da Educação, v. 04, n. 01, 2013. Disponível em: <http:// www.facsaoroque.br/novo/publicacoes/pdf/v4-n1-2013/Marcia.pdf>. Acesso em: 30 dez. 2014.

KATO, M. No mundo da escrita: uma perspectiva psicolinguística. São Paulo: Ática, 1986, $144 \mathrm{p}$.

KLEIMAN, A. B. Os significados do letramento. São Paulo: Mercado das Letras, 1995. 294p.

MANDELA, N. O caminho para a liberdade. São Paulo: 2005. Disponível em:<http://veja. abril.com.br/cronologia/mandela/index.shtml>. Acesso em: 29 jan. 2014.

MARCHA mundial de las mujeres. Kigali: 2004. Disponível em: <http://www.marchemondiale.org/qui_nous_sommes/charte/es>.Acesso em: 23 fev. 2014.

PADILHA, P. R. Educação em direitos humanos sob a ótica dos ensinamentos de Paulo Freire. In: SCHILLING, F. (Org.). Direitos humanos e educação: outras palavras, outras práticas. São Paulo: Cortez, 2005. p. 166-176.

O "Círculo de cultura" na perspectiva da intertransculturalidade. Disponível em: <http://siteantigo.paulofreire.org/pub/Crpf/CrpfAcervo000135/O_Circulo_de_Cultura_na_ perspectiva_intertranscultural.pdf $>$.Acesso em: 29 jan. 2014.

SAFFIOTI, H. O poder do macho. São Paulo: Moderna, 1987, 120 p.

SOARES, M.(Org.). Letramento: um tema em três gêneros. Belo Horizonte: Autêntica, 1998, $125 \mathrm{p}$.

Letramento e escolarização. In: Ribeiro, V. M. (Org.). Letramento no Brasil, reflexões a partir do INAF 2001 (Org.). 2. ed., São Paulo: Global, 2004, p. 89-114.

WHITAKER, D. Mulher \& homem: o mito da desigualdade. 10. ed., São Paulo: Moderna, $1997,95 \mathrm{p}$ 
Análise de uma experiência de letramento na perspectiva da educação em direitos humanos

\section{Notas}

${ }^{1}$ Artigo publicado na Revista Brasileira de Educação, v. 13, n. 37, p. 45-56, jan./abr. 2008.

2 De acordo com Padilha (2014), os "Círculos de Cultura" denominam um momento de discussão, diálogo, troca de saberes, realizado de forma coletiva, ou seja, uma forma de trabalho em grupo em que um tema é discutido com o objetivo de que se revele o contexto social e as ideologias que permeiam o assunto, exercitando o ponto de vista crítico dos participantes.

${ }^{3}$ Correspondente ao atual 70 ano do Ensino Fundamental de nove anos.

${ }^{4}$ Frase citada por Raduan Nassar na obra Lavoura Arcaica, 6. ed. São Paulo: Companhia das Letras, 1989. 204 p.

${ }^{5}$ Segundo a Marcha Mundial de Las Mujeres (2014), a "Carta Mundial das Mulheres à Humanidade" se trata de um documento apresentado no V Encontro Internacional da Marcha Mundial de Mulheres, em 2004, na qual as participantes manifestam sua posição quanto à situação da mulher e à pobreza no mundo.

${ }^{6}$ A Resolução N. 1, de 30 de Maio de 2012, que estabelece diretrizes para a implantação no currículo escolar da Educação em Direitos Humanos.

* Diretora da EMEIF do Campo Eugênio Trovatti, Araraquara, São Paulo, Brasil.

* Professora doutora da Universidade Federal de São Carlos, São Carlos, São Paulo, Brasil.

\section{Correspondência}

Cristiane Fontes de Oliveira - EMEIF do Campo Eugênio Trovatti. Rua Bento Aranha do Amaral, s/no

Distrito de Bueno de Andrada, CEP: 14812-000 - Araraquara, São Paulo, Brasil.

E-mail: cristianef-oliveira@hotmail.com - eflima281001@gmail.com

Recebido em 11 de julho de 2014

Aprovado em 31 de janeiro de 2015 